\title{
PARA UM ENTENDIMENTO DO DISCURSO SOBRE A LINGÜÍSTICA NO RS
}

\author{
Caroline Mallmann Schneiders
}

\begin{abstract}
RESUMO ${ }^{\circledR}$ : Este trabalho tem como propósito mostrar um breve percurso da Lingüística enquanto ciência, uma vez que a partir desse percurso procuramos, principalmente, chegar à forma do discurso sobre a Lingüística no RS. Para tanto, salientamos teóricos como Ferdinand de Saussure, J. Mattoso Câmara Jr., e Leonor Scliar Cabral, pois eles contribuíram para a difusão da Lingüística em diferentes épocas e lugares, bem como apontamos algumas questões que acarretaram na modificação do saber sobre e da língua.
\end{abstract}

PALAVRAS-CHAVE:

Lingüística,

institucionalização, disciplina.

\section{INTRODUÇÃO}

Este trabalho faz parte do projeto "Lingüística no sul: estudos das idéias e organização da memória”, o qual visa ao estudo das idéias lingüísticas que constituíram a significação teórica da Lingüística no RS, bem como a memória discursiva envolvida na organização deste saber.

Neste texto, buscamos destacar alguns fatos sobre o percurso da Lingüística. Com isso, trazemos em nosso estudo a questão da História das Idéias Lingüísticas, pelo viés da Análise de Discurso de linha francesa, uma vez que assim poderemos ver como, em diferentes lugares e épocas, foi delineado o discurso sobre essa ciência. Dessa forma, poderemos refletir e compreender sobre o processo da institucionalização da Lingüística no RS.

Partimos de uma reconstituição do saber que predominava no Brasil até a inserção da Lingüística no âmbito acadêmico, ou seja, o saber do gramático. A partir disso,

\footnotetext{
(c) Aluna do quinto semestre do Curso de Letras da UFSM, bolsista PIBIC/CNPq. Trabalho desenvolvido junto ao Grupo de Estudos Lingüísticos da UFSM - GEL, sob a orientação da Prof. ${ }^{a}$ Dr. Amanda Eloina Scherer.
}

"[...] através da história das idéias podemos acompanhar como certos conceitos, certas noções, certas categorias se constituíram e como ao permanecerem mudaram, ou ganharam contornos específicos." (Guimarães, 2004, p. 15)

vamos traçar alguns fatos da constituição da Lingüística enquanto ciência; destacar algumas modificações que ocorreram no saber sobre e da língua com a sua inserção no Brasil; para, enfim, chegar à forma do discurso sobre a Lingüística no RS.

Abordaremos, neste texto, teóricos como Ferdinand de Saussure, Joaquim Mattoso Câmara Jr., e Leonor Scliar Cabral, os quais se inserem em contextos diferentes, constituindo, conseqüentemente, diferentes formulações sobre o conceito do objeto de estudo da Lingüística. Assim, enfatizamos como esses teóricos concebem a língua, para, dessa forma, verificar semelhanças e diferenças entre eles.

Diante disso, o presente trabalho propõe-se a mostrar um pouco dessa trajetória da Lingüística como ciência, pois, procuramos chegar à forma do discurso sobre esse saber no RS, lugar onde foi introduzido tardiamente. Para tanto, é fundamental destacarmos os teóricos acima citados, pois suas obras foram importantes para o desenvolvimento dos estudos sobre a Lingüística em diferentes contextos, principalmente no RS.

\section{Um pouco da história da gramática}

É importante salientar que, até a instalação da Lingüística no Brasil, quem possuía o saber da língua eram os gramáticos. Eles a definiam de acordo com a postura teórica adotada, ou seja, apoiavam-se num conhecimento científico, mas não no conhecimento científico da ciência da linguagem, mais precisamente, da Lingüística (cf. ORLANDI, 2002b). Como na Lingüística, as definições dos gramáticos sobre a língua eram diversas, diferentes para cada autor, conseqüentemente, cada gramática tinha o conceito de língua conforme quem a propunha.

Desse modo, foi por intermédio dos estudos descritivos da linguagem, na década de 30 , que as questões relacionadas à língua, principalmente as questões do ensino da língua portuguesa, começaram a ser pensadas 
de maneira diferente. Um dos teóricos que mais se destacou na inserção dos estudos descritivos da linguagem, no Brasil, foi Mattoso Câmara, o qual é considerado o primeiro lingüista brasileiro.

Até os anos 50, a escola era destinada apenas para as crianças pertencentes à elite. Dessa forma, a língua que a escola privilegiava era a da camada social favorecida, pois considerava-se que esta utilizava a forma correta de falar. Com isso, as gramáticas utilizadas no ensino da língua portuguesa, eram propostas acerca da norma que a elite possuía, ou seja, da norma culta, já que somente a elite tinha acesso ao ensino. A norma culta é ainda hoje a língua visada nas gramáticas de língua portuguesa.

Sendo assim, os alunos que ingressavam na escola já entravam com certo domínio sobre a norma culta, pois estavam inseridos no contexto onde era utilizada essa forma de falar, ou seja, a norma culta fazia parte da realidade dessas crianças. A escola, até esse período, enfatizava estudos clássicos, que abrangiam o Latim e o Grego, a Retórica e a Filosofia, destinando poucas aulas para o ensino de Gramática Nacional.

Convém salientar que, nesse momento, a gramática não tinha a função de regularização do modo de falar, pois, como já foi destacado, a escola era somente para a elite, a qual já possuía certo domínio da norma culta. Com isso, os estudos gramaticais voltavam-se para "a construção do sujeito nacional, um cidadão brasileiro com sua língua própria, visível na gramática" (cf. ORLANDI, 2002b, p. 195), isto é, visava à legitimação da língua brasileira.

Observa-se, então, que a gramática não era tão necessária para o ensino da língua portuguesa. Porém, essa realidade modifica-se de maneira significativa entre os anos 50 e 60, período em que a gramática, visando à norma culta, torna-se prioridade no ensino da língua portuguesa. Um dos principais motivos que contribuiu para essa primazia foi a chamada democratização do ensino.

A democratização do ensino aconteceu a partir dos anos 50 e foi a inserção do povo em geral ao ensino. Em virtude disso, que a gramática se tornou fundamental neste período, porque esses que passaram a ter acesso ao ensino não chegavam à escola dominando a norma culta como os alunos pertencentes à elite.

Desse modo, a gramática passou a ter a função de ensinar a maneira correta da língua a esses novos alunos, uma vez que, segundo a escola, eles não sabiam falar corretamente.

Essa imposição da norma culta a quem não a exerce reflete uma dominação da elite sobre essa classe social, pois, na medida em que se impõe essa norma, objetiva-se uma padronização da língua. Assim, o que era uma legitimação da língua, passa a ser uma regularização, desconsiderando as diversas formas de se expressar (cf. ORLANDI, 2002b).

Com isso, é neste período que vai se estabelecer a Nomenclatura Gramatical Brasileira (NGB - 1957/1958), através de um decreto federal, surgindo para afirmar uma homogeneização da língua brasileira, tendo como objetivo a fixação de uma terminologia gramatical do Brasil, já que não havia regularidade nas terminologias das gramáticas até então propostas.

Através da NGB, o lingüista começa a ganhar certo reconhecimento enquanto detentor do conhecimento científico da língua, pois como os gramáticos tinham posições diversas sobre o saber da língua, sem possuir um estudo sobre a ciência da linguagem, achou-se fundamental a posição dos lingüistas diante da NGB. Assim, "a questão da língua não é mais só da competência do gramático, ela torna-se uma questão dos lingüistas" (ORLANDI, 2002a, p. 36-37).

A Lingüística, com isso, ganha prestígio perante a gramática, embora se opondo ao que ela propõe. A Lingüística visa a explicar/descrever os fatos da língua na sua diversidade, já a gramática (NGB) visa a uma terminologia uniforme, considerando-a como língua nacional, oficial (cf. ORLANDI, 2002b).

Percebemos, dessa forma, que a democratização do ensino ajudou no estabelecimento da NGB, a qual contribuiu na abertura do espaço dos lingüistas como detentores do conhecimento científico sobre e da língua. Assim, percebemos que devido às necessidades que foram aparecendo em relação ao tratamento da língua, uma vez que ela é o objeto de estudo da Lingüística, o que era no início apenas ciência, foi tomando novos rumos e inserindo-se também no âmbito da educação.

Essa inserção da Lingüística no ensino ajudará na sua institucionalização como disciplina nos cursos de formação de professores em Letras, cujo curso também possui a língua como objeto de estudo.

\section{A ciência Lingüística}


Os estudos tratando a Lingüística como ciência da linguagem começaram com o suíço Ferdinand de Saussure, e foram sistematizados em 1916, através de seus cursos, na obra Curso de Lingüística Geral. Esse livro não foi publicado por ele, é uma obra póstuma organizada por dois de seus exalunos, com anotações que foram feitas em sala de aula. As anotações originaram das aulas realizadas por Saussure, em três cursos de Lingüística Geral, ministradas em Genebra.

Para essa ciência, Saussure define como seu objeto de estudo la langue (língua), pois, para ele, somente a língua é passível de uma definição autônoma, e era justamente um objeto de caráter autônomo que ele queria definir para a ciência Lingüística. Com isso, é a partir de Saussure que se destaca o aspecto instrumental da língua, considerando-a como meio de comunicação, o que possibilitou estudá-la como sendo um produto.

Segundo Mattoso (1975), Saussure interpreta a língua como um sistema bem organizado, isto é, define-a como um sistema de signos, conjunto de unidades que estão organizadas formando um todo. Ele, então, trata a língua como sistema, o que para seus sucessores se denominará de estrutura. (ORLANDI, 2002c, p.24).

No Brasil, na década de 30 , também começam a ser esboçados estudos sobre a Lingüística Geral. Destaca-se nesses estudos Joaquim Mattoso Câmara Jr., o qual é considerado o primeiro lingüista do Brasil. Foi através do livro Princípios de Lingüística Geral, de Mattoso Câmara, publicado em 1941, que se sistematizou a Lingüística Moderna no Brasil, ou seja, passaram a ser introduzidos estudos descritivos da linguagem. Desse modo, o estudo sobre a língua, que era proposto pelo gramático, começa a ser visto sob outra perspectiva, a da Lingüística. (Altman, 2003)

Através da obra de Mattoso Câmara, observa-se que ele considera a língua como um instrumento de comunicação, o qual é utilizado pelos membros de uma comunidade. Segundo esta perspectiva de Mattoso Câmara, a língua é dependente de toda a cultura, pois, a cada momento, a cultura se reflete na língua, a qual tem a função de expressá-la.

Mattoso Câmara, em seus estudos sobre a língua, enfatiza, ao mesmo tempo, questões sobre a Lingüística Geral e sobre a Língua Portuguesa. Ao trazer juntos esses estudos, ele faz as primeiras referências sobre a relação existente entre eles, mostrando que os mesmos devem se dar de forma paralela e não separadamente. Ou seja, o ensino da Língua Portuguesa deve estar relacionado a um conhecimento científico e reconhecido, no caso, aos estudos descritivos da linguagem.

Pode-se dizer que um dos motivos para Mattoso Câmara trazer essa relação entre Lingüística e Língua Portuguesa se deve ao fato de que no Brasil, até esse momento, eram os gramáticos que detinham o saber sobre a língua, e também para destacar que o português do Brasil era diferente do português de Portugal.

Aos poucos, a Lingüística foi propagando-se por todo o território brasileiro, possuindo como principal difusor Mattoso Câmara. Levando em conta a expansão da Lingüística pelo interior do Brasil, especificamente no Rio Grande do Sul, foi na década de 70 que se sistematizou a ciência Lingüística, através da publicação do livro Introdução à Lingüística, de Leonor Scliar Cabral. Destacamos as formulações feitas por Leonor Scliar Cabral, porque seus estudos foram muito relevantes no contexto universitário sul-rio-grandense.

Em seu livro Introdução à Lingüística, Leonor Scliar Cabral não só retoma as colocações feitas por Saussure e por Mattoso, mas também considera a língua "como um modelo coletivo depositado no cérebro de cada membro de uma determinada comunidade, independente da vontade do indivíduo" (cf. CABRAL, 1976, p. 171). Para ela, a língua, além de ser um sistema de elementos destinado à comunicação, é um modelo, ou seja, possui uma forma definida que se formaliza no signo lingüístico.

Leonor Scliar Cabral, ao considerar a língua como forma, faz referência, de certo modo, ao que Mattoso enfatiza, ou seja, que a função da língua é expressar a cultura, para permitir a comunicação social. Pois, se um indivíduo ao utilizar a língua não usar o modelo, isto é, a forma da determinada comunidade em que está inserido, ele não expressará a sua cultura e poderá não exercer a comunicação social, também enfatizada por Saussure.

Isto posto, observamos que as definições dadas à língua, de uma época para outra, modificam-se em algum ponto. Isso acontece devido ao fato de os teóricos abordarem nos conceitos a sua perspectiva, isto é, o seu ponto de vista diante das definições já postas. Dessa forma, é o contexto em que cada teórico está inserido e a sua visão do mundo, que vão determinar a sua postura, acarretando nas diversas definições 
sobre um conceito, não só de uma época para outra, mas também na mesma época.

Percebemos, então, que em vários pontos as definições dos três teóricos assemelham-se. No entanto, cada abordagem é diferente, estando de acordo com a ideologia que cerca cada teórico, uma vez que pertencem a épocas e lugares diferentes. Logo, o conceito de língua modifica-se em cada contexto, de acordo com a perspectiva discursiva, porque muda a sua relação com a formação ideológica, que é o conjunto de idéias de uma dada formação social. Através das formulações dos teóricos anteriormente referidos, percebe-se que todo discurso remete a um já-dito, ou seja, todo dizer vai estar ancorado, em algum ponto, em outros dizeres.

\section{A disciplina de Lingüística nos cursos de Letras do Brasil}

A criação de um novo espaço institucional, de nível superior, se propiciou a profissionalização daqueles que cumpriam o programa de investigação proposto pela Filologia, propiciou, igualmente que se instalasse no país, pela primeira vez junto a um Curso de Letras, um curso extensivo de Lingüística, ministradas por Mattoso Câmara, em 1938 e 1939, na então chamada Faculdade de Filosofia e Letras da Universidade do Distrito Federal, no Rio de Janeiro. (ALTMAN, 2003, p. 101)

Considerando a passagem acima, observamos que os estudos de Mattoso Câmara iniciaram na mesma época da criação dos cursos superiores de Letras, na década de 30. Em virtude de Mattoso trabalhar com estudos sobre a língua através da Lingüística, assim como a Filologia, ele se torna 0 professor que coordenou o primeiro curso regular de Lingüística Geral. Então, é Mattoso Câmara quem faz as primeiras referências à importância dos estudos lingüísticos nos cursos superiores de Letras.

Outra questão que se evidencia é que a Lingüística, na década de 30 , entrou nos cursos superiores de Letras junto à disciplina de Filologia. Como salienta Altman (2003), os Filólogos não aceitaram a inserção da Lingüística como parte da disciplina de Filologia, uma vez que esta tratava a língua como diacrônica e visava seu estudo histórico, ao contrário da Lingüística. Com isso, a Lingüística divulgou-se através da Filologia nas décadas de 40 e 50, de forma proibida nos cursos de Letras, mas mesmo assim a Lingüística foi ganhando espaço, até tornar-se numa disciplina autônoma.

Foi somente nos anos 60 que se propagaram os cursos de Lingüística pelo país. É nesse período que os estudos estruturalistas atingem a maior repercussão, acarretando no maior número de reedições e traduções da obra de Saussure, Curso de Lingüística Geral, em virtude de ser a primeira obra sobre Lingüística Geral a ser sistematizada; e também das obras de Mattoso Câmara, Princípios de Lingüística Geral e Estrutura da Língua Portuguesa, já que este é o primeiro lingüista brasileiro e quem introduziu a questão da estrutura da língua no país.

Através da Lingüística Estrutural de Mattoso, constatou-se que o programa da disciplina de Lingüística era diferente do programa da Filologia, de modo que a Lingüística não podia ser inserida junto à Filologia. Isso acarretou na formação de uma disciplina autônoma de Lingüística nos cursos superiores de Letras. Em virtude do crescimento da Lingüística perante a Filologia, aconteceu, neste período, "uma disputa entre essas duas disciplinas pela hegemonia dos espaços institucionais disponíveis" (ALTMAN, 2003, p.107).

Contudo, a Lingüística apenas é introduzida como disciplina obrigatória nos cursos de Letras em 1965, ocasionando o início do espaço de pesquisa sobre questões da linguagem. Percebe-se que este período é posterior à democratização do ensino e ao estabelecimento da NGB, e como não é mais o gramático quem produz o conhecimento sobre a língua e sim os lingüistas,

\begin{abstract}
cabe à Lingüística justamente a função de ordenar a construção e as produções de um saber sobre língua a serem estudadas nos currículos dos cursos, dando-lhes uma caracterização sistêmica que, se nem sempre é a mais adequada, permite ao menos que se pense a língua como um fenômeno lingüístico no associado à história dos sujeitos e da sociedade. (SCHERER, 2005, p. 14)
\end{abstract}

Sendo assim, a ciência passa a se moldar de acordo com as necessidades do momento pelo qual o contexto brasileiro estava passando. Então, é devido à relevância e à exigência de se ter professores especializados 
no conhecimento do saber sobre a língua, já que não é mais o gramático o encarregado dessa função, que a ciência Lingüística se expandiu para outro terreno, o dos cursos de Letras.

Foi, então, com o surgimento da necessidade do estudo sobre e da língua, que a Lingüística passou a ser pensada também no âmbito acadêmico, até tornar-se uma disciplina essencial nos cursos de formação de professores em Letras.

Considerando 0 interior do Brasil, precisamente o Rio Grande do Sul, a fundação dos cursos de Letras aconteceu tardiamente, comparando com o centro do Brasil, apenas entre os anos 50/60, mesmo período em que ocorreu a democratização do ensino, o estabelecimento da NGB, e o auge da Lingüística Estrutural.

Pode-se dizer que a instalação do curso de Letras no RS se deu em virtude da necessidade urgente de professores especializados no ensino da Língua portuguesa, já que a demanda da escola passou a ser outra.

Como os cursos de Letras, a disciplina de Lingüística também foi introduzida mais tarde nos currículos dos cursos de Letras do RS, apenas em 1967, juntamente com o momento da sistematização da ciência no estado. Dessa forma, observa-se que no contexto sul-rio-grandense, diante das modificações frente ao ensino, a Lingüística como ciência possuía um discurso teórico, mas embasado nas questões do ensino, ou seja, estava mais voltado aos cursos de formação de professores em Letras.

Constata-se isso, através da obra Introdução à Lingüística, de Leonor Scliar Cabral. Essa obra originou-se de textos da teórica, que circularam no Jornal Diário de Notícias, entre 1966 e 1967. Tal livro tinha como alvo alunos do início da graduação, principalmente, em Letras e Comunicação. Dessa forma, percebe-se que Leonor Scliar Cabral visava a uma Lingüística institucionalizada como disciplina no RS, constituindo-se como uma Lingüística Aplicada.

Há um deslocamento, por assim dizer, no saber da Lingüística, pois no momento em que, no RS, dá-se uma nova abordagem ao sentido dessa ciência, abre-se um novo espaço de circulação desse saber, o espaço educacional, configurando-se numa Lingüística voltada para o ensino. Com isso, cria-se uma nova perspectiva para os estudos lingüísticos do RS.
Dessa forma, em conformidade com Altman, "foi a partir de 1968 que se concentrou um conjunto de fatores de ordem intelectual e social que permitiu, em vários pontos do país, a solidificação institucional de uma "Lingüística brasileira" e de um jovem grupo de pesquisadores que começaram, a partir de então, a se reconhecer lingüistas" (2003, p. 47). Altman traz essa questão, uma vez que as pesquisas sobre a Lingüística aconteciam de forma fragmentada e por iniciativa individual. Essa realidade começa a mudar a partir dos anos 60, quando grupos de estudiosos mobilizam-se e passam a oferecer cursos e a organizar Institutos de Lingüística para difundila.

Percebemos, com isso, que a expansão, tanto dos cursos de Letras, quanto da Lingüística como disciplina nos seus currículos, não foi algo que se desenvolveu pelo território brasileiro de forma natural e linear, mas devido a acontecimentos significativos, que propiciaram as modificações e os processos que a Lingüística sofreu.

\section{CONCLUSÃO}

Assim, a Lingüística teve como ponto de partida e base para todos os estudos descritivos da linguagem as formulações de Saussure. No Brasil, este lugar pertence a Mattoso Câmara, o qual contribuiu com diversos estudos sobre a língua, possuindo um lugar de destaque neste primeiro momento dos estudos lingüísticos no Brasil. No RS, Leonor Scliar Cabral se destaca, principalmente, enquanto referência aos cursos de formação em Letras.

Buscamos traçar nesse texto, um breve esboço da trajetória da Lingüística, o qual é relevante para entender 0 porquê de a Lingüística se transformar em disciplina. Com isso, a Lingüística fixa-se como sendo um discurso sobre a língua, pois, como observamos, através de sua trajetória, ela tornou-se uma instância fundamental para a institucionalização de seu sentido.

Depreendemos, através do percurso que traçamos, que o discurso sobre a ciência Lingüística, quando chegou ao RS, tornou-se diferente dos outros lugares. Neste contexto, a Lingüística surgiu ligada à outra realidade, a uma necessidade que se colocou diante do ensino, constituindo-se, desse modo, numa Lingüística voltada para a institucionalização da disciplina no RS, denominando-se de Lingüística Aplicada. 
Logo, entendemos que é de suma importância compreender tanto o percurso, como os processos que surgiram em relação à Lingüística e aos cursos de Letras, já que ambos possuem a linguagem como objeto de estudo e tornam-se a base para o surgimento dos cursos de pós-graduação, que têm a função de especializar os professores graduados em Letras na área da Lingüística, para que eles tenham a titulação necessária para ministrar tal disciplina nos cursos superiores de Letras.

\section{REFERÊNCIAS BIBLIOGRÁFICAS}

SAUSSURE, Ferdinand de. Curso de lingüística Geral. São Paulo: Cultrix, 1975.

CÂMARA, Mattoso. Princípios de Lingüística Geral. Rio de Janeiro: Acadêmica, 1969.

CÂMARA, Mattoso. História da Lingüística. São Paulo: Vozes, 1975.

CABRAL, Leonor Scliar. Introdução à Lingüística. Porto Alegre: Globo, 1973.
ORLANDI, Eni P. e GUIMARÃES Eduardo (orgs.). Institucionalização dos Estudos da Linguagem: a disciplinarização das Idéias Lingüísticas. Campinas, São Paulo: Pontes, 2002 (a).

ORLANDI, Eni P. Língua e conhecimento Lingüístico: para uma história das idéias. São Paulo: Cortez, 2002 (b).

Análise do discurso: Princípios e procedimentos. Campinas. São Paulo: Pontes, 2001.

O que é Lingüística. São Paulo: Brasiliense, 2002 (c).

SCHERER, Amanda Eloina. Lingüística no sul: estudo das idéias e organização da memória. In: Eduardo Guimarães e Mirian Rose Brumde-Paula (orgs.). Sentido e Memória. Campinas: Pontes editores, 2005.

ALTMAN, Cristina. A pesquisa lingüística no Brasil (1968-1988). São Paulo: Humanitas, 2003. 